\title{
Comparison of transcriptional responses in liver tissue and primary hepatocyte cell cultures after exposure to hexahydro-I, 3,
} 5-trinitro-I, 3, 5-triazine Edward J Perkins' ${ }^{* 1}$, Wenjun $\mathrm{Bao}^{2}$, Xin Guan ${ }^{3}$, Choo-Yaw Ang ${ }^{3}$,
Russell D Wolfinger ${ }^{2}$, Tzu-Ming $\mathrm{Chu}^{2}$, Sharon A Meyer ${ }^{4}$ and Laura S Inouye ${ }^{1}$

Address: ${ }^{1}$ US Army Engineer Research and Development Center, 3909 Halls Ferry Road, Vicksburg, MS, USA, ${ }^{2}$ SAS Institute Inc, SAS Campus Drive, Cary, NC, USA, ${ }^{3}$ SpecPro, Vicksburg, MS, USA and ${ }^{4}$ University of Louisiana at Monroe, Monroe, LA, USA

Email: Edward J Perkins* - edward.j.perkins@us.army.mil; Wenjun Bao - wenjun.bao@sas.com; Xin Guan - xin.guan@us.army.mil; ChooYaw Ang - choo.y.ang@us.army.mil; Russell D Wolfinger - russ.wolfinger@sas.com; Tzu-Ming Chu - tzu-ming.chu@sas.com; Sharon A Meyer - meyer@ulm.edu; Laura S Inouye - laura.s.inouye@us.army.mil

* Corresponding author

from Symposium of Computations in Bioinformatics and Bioscience (SCBB06) in conjunction with the International Multi-Symposiums on Computer and Computational Sciences 2006 (IMSCCS|06)

Hangzhou, China. June 20-24, 2006

Published: 12 December 2006

BMC Bioinformatics 2006, 7(Suppl 4):S22 doi:10.1186/I47I-2105-7-S4-S22

(c) 2006 Perkins et al; licensee BioMed Central Ltd

This is an open access article distributed under the terms of the Creative Commons Attribution License (http://creativecommons.org/licenses/by/2.0), which permits unrestricted use, distribution, and reproduction in any medium, provided the original work is properly cited.

\begin{abstract}
Background: Cell culture systems are useful in studying toxicological effects of chemicals such as Hexahydro-I,3,5-trinitro-I,3,5-triazine (RDX), however little is known as to how accurately isolated cells reflect responses of intact organs. In this work, we compare transcriptional responses in livers of Sprague-Dawley rats and primary hepatocyte cells after exposure to RDX to determine how faithfully the in vitro model system reflects in vivo responses.

Results: Expression patterns were found to be markedly different between liver tissue and primary cell cultures before exposure to RDX. Liver gene expression was enriched in processes important in toxicology such as metabolism of amino acids, lipids, aromatic compounds, and drugs when compared to cells. Transcriptional responses in cells exposed to $7.5,15$, or $30 \mathrm{mg} / \mathrm{L}$ RDX for 24 and 48 hours were different from those of livers isolated from rats 24 hours after exposure to 12,24 , or $48 \mathrm{mg} / \mathrm{Kg}$ RDX. Most of the differentially expressed genes identified across conditions and treatments could be attributed to differences between cells and tissue. Some similarity was observed in RDX effects on gene expression between tissue and cells, but also significant differences that appear to reflect the state of the cell or tissue examined.

Conclusion: Liver tissue and primary cells express different suites of genes that suggest they have fundamental differences in their cell physiology. Expression effects related to RDX exposure in cells reflected a fraction of liver responses indicating that care must be taken in extrapolating from primary cells to whole animal organ toxicity effects.
\end{abstract}




\section{Background}

RDX is known to contaminate soil and ground water associated with munitions manufacturing and artillery training sites [1], some of which are listed on the National Priorities List by the U.S. Environmental Protection Agency [2]. RDX has also been targeted for future regulatory action under provisions of the Safe Drinking Water Act [3]. Human health effects of RDX are well known to include the central nervous system as the critical target tissue for acute exposure to high doses as manifested by reversible seizure activity [2,4-6]. While many effects of RDX exposure are known, little is known about the mechanisms by which it causes toxicity.

Primary cell cultures offer several advantages over animals in determining mechanisms of chemical toxicity. Primary hepatocyte cells are freshly prepared from liver tissue by proteolytic digestion and enrichment of hepatocyte cells through centrifugation. These cells enable high throughput testing methods to examine toxicity. Primary cell cultures can reduce concerns such as animal availability, cost, and welfare that limit the application of in vivo studies of chemical effects. However, the responses to chemical exposure in isolated cells may not reflect those of intact organs in animals especially as organs are often composed of more than one cell type potentially complicating direct comparisons. Liver cell populations consist of approximately 85\% hepatocytes along with other cell types: Kupfer (macrophage) cells, vascular endothelial cells and "Ito" cells (a myeloepithelial cell) [7]. In addition, conservation of gene expression patterns in hepatocytes isolated from livers have been shown to diverge from liver tissue as the cells adapt to culture conditions [8,9] and may respond to chemicals in a manner different from liver tissue $[10]$.

We examined in vitro exposed primary hepatocyte cells and in vivo exposed rat liver tissue to understand how the transcriptional responses of these systems compared after exposure to RDX. Gene expression was analyzed in primary cell cultures exposed to 7.5, 15, or $30 \mathrm{mg} / \mathrm{L}$ RDX for 24 and 48 hours. Primary cell expression effects were compared to those in liver tissue isolated from female Sprague-Dawley rats 24 hours after gavage with 12, 24, or $48 \mathrm{mg} / \mathrm{Kg}$ RDX. Samples were assessed within time point and cell type ( $24 \mathrm{hr}$ cell, $48 \mathrm{hr}$ cell, and liver tissue) to their respective controls using a loop design and 2-color, 8 K gene microarrays.

\section{Results}

We have examined the gene expression responses in primary hepatic cells freshly isolated from liver tissue. Exposure concentrations for transcriptional profiling of cells were selected based on the results of cytotoxicity assays, which indicated a complete lack of cytotoxicity at all levels of RDX tested. Concentrations to which cells were exposed were similar to the $8.4 \mathrm{mg} / \mathrm{kg}$ tissue found in liver $24 \mathrm{hrs}$ after dosing with $47 \mathrm{mg} / \mathrm{Kg}$ RDX (data not shown) given the assumption that tissue is approximately $80 \%$ water and $1 \mathrm{gm} / \mathrm{ml}$ resulting in concentration of approximately $42 \mathrm{mg} / \mathrm{L}$ water.

\section{Comparison of expression in unexposed cells and tissue}

Gene expression was assessed using an oligonucleotide microarray capable of detecting 7616 different rat genes. Twenty five percent of all genes on the array were detected in control liver tissue, $48 \%$ of all genes in $24 \mathrm{hr}$ control primary cells, and $66 \%$ of all genes in $48 \mathrm{hr}$ control primary cells. Analysis of GO biological process terms associated with genes expressed in controls indicated significant differences both in the variety and type of biological processes present in cells and tissues prior to chemical exposure. Liver tissues were associated with 305 different terms with terms related to amino acid metabolism and catabolism, lipid and fatty acid metabolism, and aromatic and drug metabolism being unique to liver cells. $24 \mathrm{hr}$ cells were associated with 398 different terms with terms related to cell division, organ development, response to DNA damage unique to $24 \mathrm{hr}$ cells. Forty eight hr cells were associated with 587 GO biological process terms with terms related to cell cycling, protein modification, alkene metabolism, neural cell development, signalling, and regulation in addition to organ and cell differentiation, organization, and development. Comparison of expressed genes in tissues and cells versus the list of those on an array can also reveal functions that are enriched in each particular cells type (Table 1). Relative to cells, liver tissues were significantly enriched in lipid, fatty acid and steroid metabolism, electron transport, oxidative phosphorylation, and cell adhesion-mediated signalling. Twenty four hr cells were significantly enriched in protein folding, vesicle transport, protein traffic, and nucleic acid metabolism when compared to $48 \mathrm{hr}$ cells and liver tissue. Forty eight hr cells were enriched for genes involved in proteolysis and circulation in comparison to $24 \mathrm{hr}$ cells and liver tissue.

\section{Comparison of expression in RDX exposed cells and tissue} The overall response of different tissues or cells to chemical exposure can be compared by determining the percentage of genes that were actually expressed. When the number of genes present on the array that were expressed in tissues or cells as determined by present/absent calls across all doses of RDX were compared, cell cultures were found to express a larger percentage of genes. Across all doses of RDX, 54\% of the genes present on the array were expressed in liver, $62 \%$ of all possible genes on the array were expressed by primary hepatic cells at 24 hrs and $68 \%$ at 48 hrs of exposure to RDX. Primary cells at 24 hrs across all doses of RDX were more similar ( $88 \%)$ to overall liver 
Table I: Comparison classes of genes expressed in liver, $24 \mathrm{hr}$ cells and $48 \mathrm{hr}$ cells reveal significant differences between tissue and isolated cells.

\begin{tabular}{|c|c|c|c|c|c|c|}
\hline \multirow[t]{2}{*}{ Biological Process } & \multicolumn{2}{|c|}{ Liver } & \multicolumn{2}{|c|}{$24 \mathrm{hr}$ Cells } & \multicolumn{2}{|c|}{$48 \mathrm{~h}$ Cells } \\
\hline & over/under & P-value & over/under & P-value & over/under & P-value \\
\hline \multicolumn{7}{|l|}{ Liver and Primary cells } \\
\hline Signal transduction & + & I.02E-2। & + & 3.7IE-I4 & + & $1.29 \mathrm{E}-10$ \\
\hline Cell surface receptor mediated signal transduction & + & $7.35 \mathrm{E}-12$ & + & I.16E-09 & + & I.65E-07 \\
\hline Cell communication & + & 9.37E-09 & + & $3.93 \mathrm{E}-06$ & + & 4.89E-03 \\
\hline Neuronal activities & + & $6.85 \mathrm{E}-08$ & + & $3.36 \mathrm{E}-08$ & + & 3.63E-05 \\
\hline G-protein mediated signaling & + & $9.33 \mathrm{E}-07$ & + & I.42E-08 & + & 2.47E-06 \\
\hline Ion transport & + & $8.51 \mathrm{E}-06$ & + & 7.03E-09 & + & 1.34E-02 \\
\hline Cation transport & + & $2.84 \mathrm{E}-05$ & + & I.52E-07 & + & I.2IE-02 \\
\hline Synaptic transmission & + & I.7IE-04 & + & $8.40 \mathrm{E}-04$ & + & 4.46E-02 \\
\hline Developmental processes & + & $1.43 \mathrm{E}-05$ & + & I.7IE-04 & + & 3.|IE-0I \\
\hline Protein biosynthesis & - & $1.68 \mathrm{E}-10$ & - & $2.15 \mathrm{E}-09$ & - & $1.00 \mathrm{E}+00$ \\
\hline Cell adhesion & + & $6.52 \mathrm{E}-03$ & + & $4.22 \mathrm{E}-03$ & + & $1.00 \mathrm{E}+00$ \\
\hline \multicolumn{7}{|l|}{ Liver only } \\
\hline Electron transport & - & 4.IIE-09 & - & $5.13 \mathrm{E}-02$ & - & $6.33 \mathrm{E}-0 \mathrm{I}$ \\
\hline Lipid, fatty acid and steroid metabolism & - & $4.38 \mathrm{E}-05$ & + & $1.00 \mathrm{E}+00$ & - & $1.00 \mathrm{E}+00$ \\
\hline Steroid metabolism & - & I.56E-04 & - & $1.00 \mathrm{E}+00$ & - & $1.00 \mathrm{E}+00$ \\
\hline Ligand-mediated signaling & + & $3.48 \mathrm{E}-04$ & + & I.07E-0| & + & $1.00 \mathrm{E}+00$ \\
\hline Fatty acid metabolism & - & $7.4 \mid \mathrm{E}-04$ & - & $1.00 E+00$ & - & $1.00 \mathrm{E}+00$ \\
\hline Coenzyme and prosthetic group metabolism & - & I.45E-02 & - & $1.00 \mathrm{E}+00$ & + & $1.00 \mathrm{E}+00$ \\
\hline Oxidative phosphorylation & - & $2.40 \mathrm{E}-02$ & - & $7.57 \mathrm{E}-0 \mathrm{I}$ & - & $1.00 \mathrm{E}+00$ \\
\hline Protein phosphorylation & + & $3.10 \mathrm{E}-02$ & - & $1.00 \mathrm{E}+00$ & - & $1.00 \mathrm{E}+00$ \\
\hline Cell adhesion-mediated signaling & + & $3.80 \mathrm{E}-02$ & + & $3.37 \mathrm{E}-01$ & + & $1.00 \mathrm{E}+00$ \\
\hline \multicolumn{7}{|l|}{ Primary cells } \\
\hline Protein metabolism and modification & - & $6.79 \mathrm{E}-02$ & - & $2.47 \mathrm{E}-04$ & - & 3.27E-03 \\
\hline Transport & + & $6.85 \mathrm{E}-02$ & + & 4.22E-06 & + & $1.33 \mathrm{E}-02$ \\
\hline Protein folding & - & I.IIE-0I & - & $1.94 \mathrm{E}-03$ & - & $1.00 \mathrm{E}+00$ \\
\hline General vesicle transport & - & $1.00 \mathrm{E}+00$ & - & $4.3 \mathrm{IE}-02$ & - & $1.00 \mathrm{E}+00$ \\
\hline Intracellular protein traffic & - & $1.00 \mathrm{E}+00$ & - & $\mathrm{I} .12 \mathrm{E}-03$ & - & $1.00 \mathrm{E}+00$ \\
\hline Nucleoside, nucleotide and nucleic acid metabolism & - & $1.00 \mathrm{E}+00$ & - & $1.68 \mathrm{E}-02$ & - & $1.00 \mathrm{E}+00$ \\
\hline Proteolysis & - & I.55E-0| & - & $1.00 \mathrm{E}+00$ & - & $4.39 \mathrm{E}-02$ \\
\hline Blood circulation and gas exchange & - & $1.00 \mathrm{E}+00$ & + & $6.59 \mathrm{E}-0 \mathrm{I}$ & + & $8.90 \mathrm{E}-03$ \\
\hline
\end{tabular}

Each list of genes present in liver or cells was compared to the reference list of all possible genes detectable by the microarray using the binomial test (18) for each molecular function, biological process, or pathway term in PANTHER http://www.pantherdb.org. An over (+) or under (-) representation of PANTHER classification categories was considered significant when $\mathrm{P}$-value $<0.05$.

tissue expression patterns than primary cells at 48 hrs $(79 \%)$ when common expressed genes are examined. This data indicates that the cells are able to express many of the same genes expressed in liver tissues, a prerequisite for establishing similar responses.

Hierarchical clustering analysis of the correlation matrix of the normalized microarray ratio data shows clustering according to tissue and exposure type. The correlation of expression between and within samples suggests that tissues and cells are responding differently to RDX exposure (Figure 1). Principal components analysis of the same correlation matrix indicates that some similarity does exist between liver and cells exposed to RDX for 24 hrs (Figure 2). After fitting a mixed linear model to each gene, the resulting volcano plots (Figure 3 ) demonstrated that the numbers of significant differentially expressed genes
(DEG) between the conditions (Figure 3D, 3E, 3F) were substantially more than the numbers of DEG due to the high dose treatment within the conditions (Figure 3A, 3B, $3 \mathrm{C})$. This indicates that different conditions, including between liver tissue and cell cultures, and between cell culture conditions, had greater impact on the gene expression profiles than the treatment. Hierarchical clustering analysis of significant DEG with Bonferroni correction using ANOVA also indicates that $24 \mathrm{hr}$ exposed cells are most similar to liver tissue with little overlap between treatments and cell timepoints (Figure 4).

We used the abundance of genes in common between differentially expressed gene lists to compare the responses of primary cell and liver tissue to RDX exposure (Figure 5). Depending on the significance level used to identify significant genes, up to $6.4 \%$ of the differentially expressed 

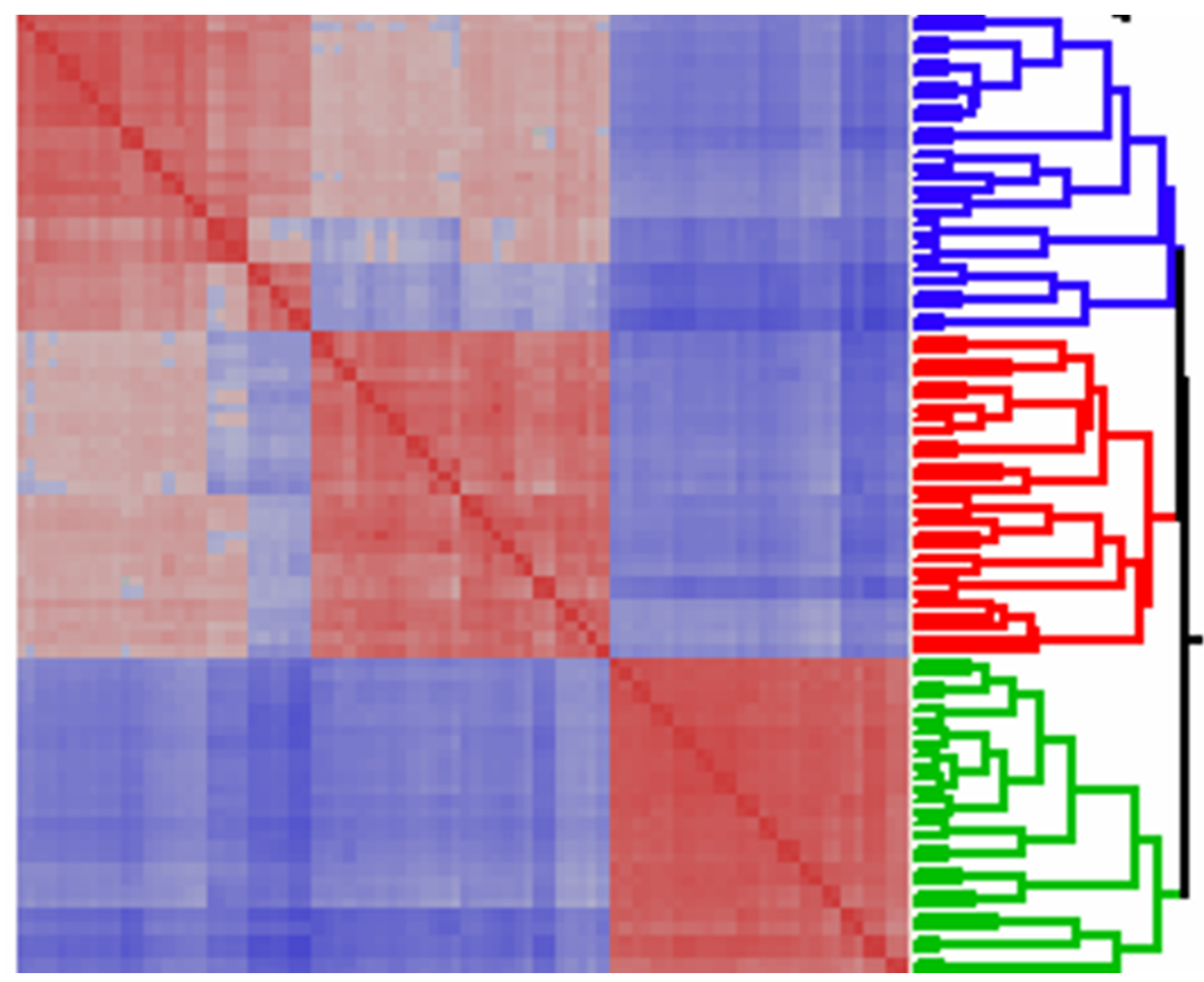

Rat 24 hour

\section{Cell 24 hour}

Cell 48 hour

\section{Figure I}

Hierarchical clustering analysis of the correlation matrix of normalized data. Blue squares represent low correlations and red represents high correlations.

genes in liver tissue at all exposures were also differentially expressed in $24 \mathrm{hr}$ primary cells at all exposures. Forty eight hr primary cells were less similar in differential expression to liver with up to $5.5 \%$ of genes differentially expressed in common with liver.

Analysis of differentially expressed genes held in common between conditions is a good indicator of relatedness. Functional biological pathways often consist of multiple genes. Therefore identification of shared pathways can be a more robust approach to comparing conditions. We compiled lists of pathways containing differentially expressed genes using EASE to identify pathways in the Kyoto Encycloaedia of Genes and Genomes (KEGG). Approximately $8.2 \%$ of affected genes had identifiable KEGG pathways. Twenty four hr exposed primary cells shared up to $78.4 \%$ of the pathways found to be affected in liver tissue (Figure 6). $48 \mathrm{hr}$ exposed cells shared up to $44.3 \%$ of pathways with liver tissues.

The proteosome/protein and degradation KEGG pathway was identified as significantly enriched in treated liver tissues (EASE score 0.004). Glutathione metabolism and valine, leucine and isoleucine degradation were enriched in $24 \mathrm{hr}$ treated cells (EASE scores 0.048 and 0.048 ). No significantly enriched pathways were detected in $48 \mathrm{hr}$ treated cells. Liver and $24 \mathrm{hr}$ treated cells were similarly enriched in GO terms such as main pathways of carbohydrate metabolism/energy derivation by oxidation of organic compounds, and macromolecule biosynthesis. Significant functional differences between primary cells and liver tissue were observed in enriched GO terms not held in common between conditions (Table 2).

Significantly changed genes in individual doses and exposure times of primary cells were compared to those found in different dose treatments of RDX. This comparison was performed to identify which dose and exposure time combination in primary cells was most similar to effects seen in liver tissue. Effects observed at $30 \mathrm{mg} / \mathrm{L}$ RDX for $24 \mathrm{hrs}$ exposure had the highest number of genes in common with liver tissues at any dose of RDX.

\section{Discussion}

We have compared the responses of an in vitro model system, primary hepatocyte cells, to that of livers in whole animals to determine the extent to which the model system faithfully represents in vivo effects. Primary hepatic cells expressed (as defined by presence absence calls) up to $88 \%$ of the same genes expressed by in vivo liver tissues 


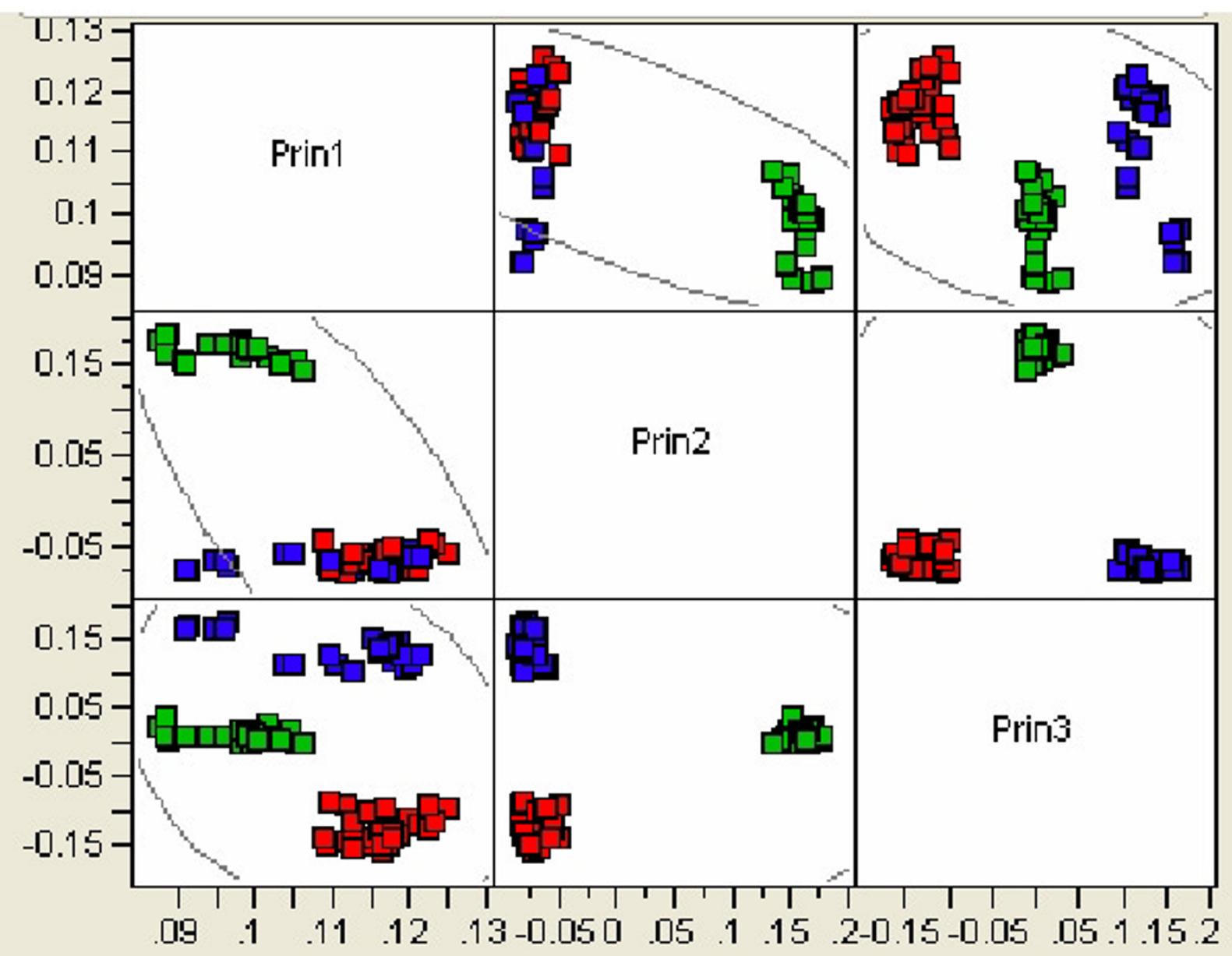

Figure 2

Principal components analysis of relatedness between microarray data. Each colored box represents an individual hybridization. Blue $=$ liver tissue, Red $=24 \mathrm{hr}$ exposed cells, and Green $=48 \mathrm{hr}$ exposed cells. Prin I $=$ first principal component, Prin2 = second principal component, and Prin3 = third principal component.

when all control and RDX doses treatments were considered. The overlap in expressed genes indicates a significant conservation of global gene expression between the two systems. This is consistent with observations of others where primary hepatocyte cells maintained $80 \%$ similarity to liver tissue in global gene expression [8]. However comparison of expression in unexposed cells and tissue also illustrates significant functional differences that may exist between the different systems. The similarity of the in vivo and in vitro systems may be dependent upon length of time that the hepatocytes had been isolated from liver tissue rather than exposure time to toxicant. The similarity of basal gene expression in primary hepatocytes to that of liver has been shown to decrease as the isolated cells adapt to conditions in culture $[8,9]$.

The overall similarity of responses of primary cells and liver tissue to RDX exposure was far less conserved than global presence and absence of expressed genes. Liver tissue responded differently to RDX than primary cells. Less than $6.4 \%$ of differentially expressed genes found in liver were also found in $24 \mathrm{hr}$ or $48 \mathrm{hr}$ primary cell exposures. This result is consistent with what Boess et al. [10] found, i.e. the limited overlap of significant DEGs from liver and two cell lines. However, the use of a p-value based rule for gene selection is not designed to maximize overlap; rather, it targets controlling the false positive rate in the final list. We used a conservative Bonferroni cutoff to provide strict control on the false positive rate. Even with this strict cutoff, almost 3000 genes were considered differentially expressed. Boess et al. [10] further cautioned about the comparison of the gene-to-gene basis between in vitro and in vivo systems. Studies comparing tumor tissues and tumor derived-cell lines have also indicated the considerable differences exist in gene expression between tissues and cell lines $[11,12]$. 


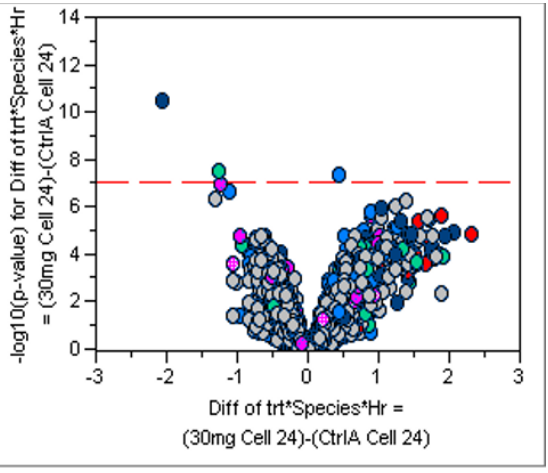

A

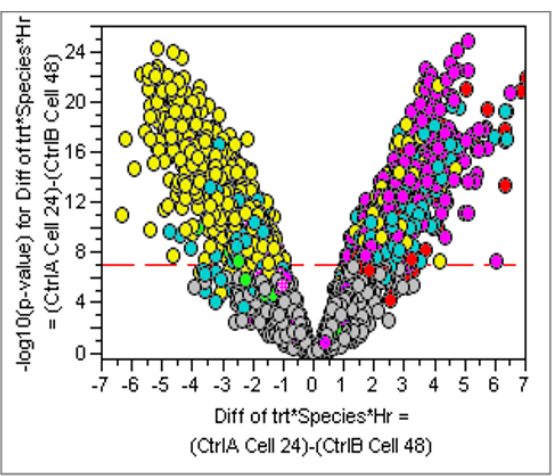

D

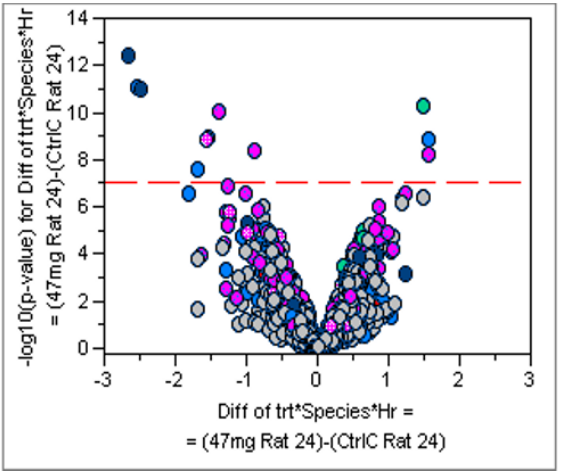

$\mathrm{B}$

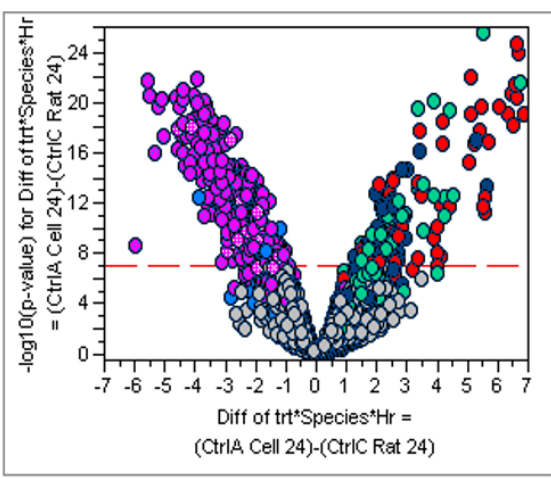

E

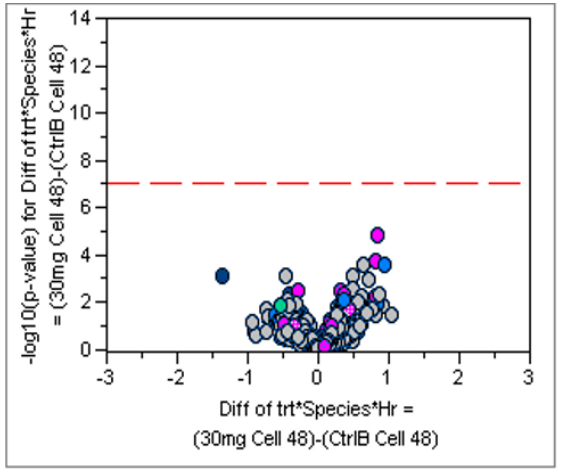

C

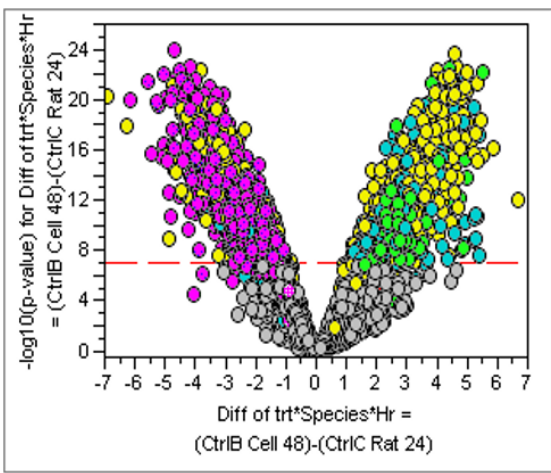

$\mathrm{F}$

Figure 3

Volcano plot illustrating predominant sources of differentially expressed genes. Differentially expressed genes are highlighted according to a Bonferroni cutoff (red dashed line) between the high dose treatments and controls within the condition e.g. $24 \mathrm{hr}$ cell $(A), 48 \mathrm{hr}$ cell $(B)$ and rat $(C)$, and between the controls of the three conditions $((24 \mathrm{hr}$ cell $-48 \mathrm{hr}$ cell $(\mathrm{D})$, $24 \mathrm{hr}$ cell -rat $(\mathrm{E})$, and $48 \mathrm{hr}$ cell -rat $(\mathrm{F}))$.

Biological functions enriched in differentially expressed gene lists highlight potentially major differences between primary cell physiology and liver tissue (Figure 4, Tables 1 and 2). General pathways and functions that were overrepresented in both liver tissue and $24 \mathrm{hr}$ treated primary cells were involved in carbohydrate metabolism, and macromolecule biosynthesis. Enriched functions affected in $24 \mathrm{hr}$ exposed primary cells that were not shared with liver were principally involved in cell growth, division, and proliferation (Figure 4). In $48 \mathrm{hr}$ treated cells, protein degradation, fatty acid transport and transcriptional activity were enriched. In addition, several genes involved in apoptosis were differentially expressed although not significantly enriched in $48 \mathrm{hr}$ treated cells. Liver tissues were enriched in pathways related to ubiquitin dependent protein catabolism, lipid and protein metabolism, oxido/ reductase activity and transferase activity on nitrogen containing groups. These differences may be due to certain pathways being induced due to the trauma of cell isolation and adaptation to culturing conditions (cell prolifer- ation, etc.), which overwhelms any response to the xenobiotics. Alternatively, it may a consequence of biotransformation-related genes whose expression are known to be down-regulated after cell isolation, such as P450s. This in turn can alter both the duration of exposure and the compounds to which the cells and/or liver are being exposed. Lastly, one cannot discount the potential involvement of other organ systems in the whole organism that are difficult to model with a single cell system. For example the toxicological activation of 2,4-dinitrotoluene has been shown to be a multi-step process involving metabolism in the liver, excretion into the bile, deconjugation of metabolites and further metabolism by the intestinal flora, re-uptake (enterohepatic transport) of metabolites into liver, and finally activation and binding to cellular macromolecules in the liver [13]. The absence of enrichment of functions related to metabolizing nitrogenous groups in $24 \mathrm{hr}$ or $48 \mathrm{hr}$ primary cells suggests that, at these time points, the hepatocyte cells reflect a limited 

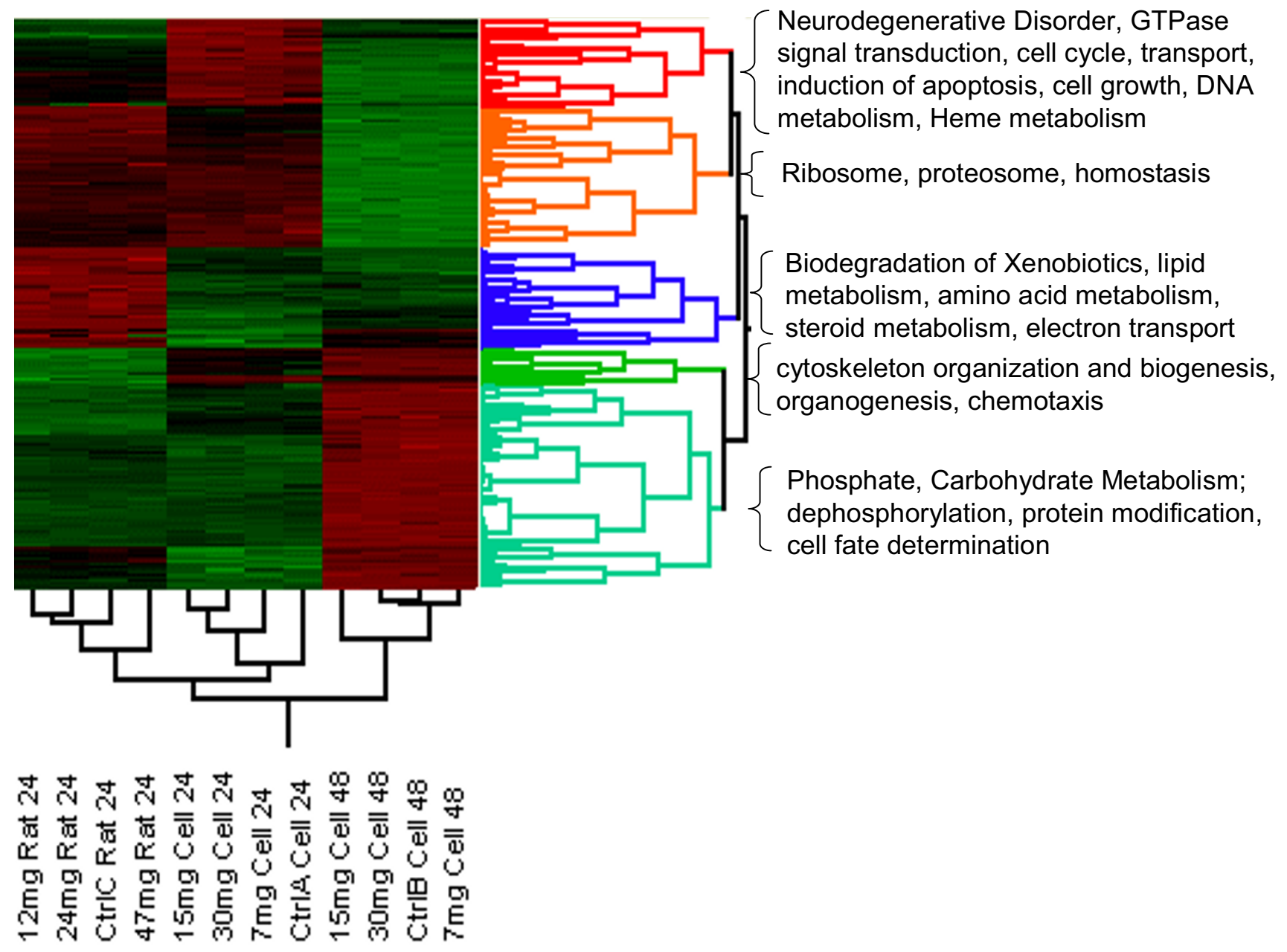

\section{Figure 4}

Hierarchical clustering of significant differentially expressed genes according to Bonferroni correction, total 2929 genes. Red represents up and green represents down-regulated genes relative to the mean of all samples. Cluster enriched GO terms are listed adjacent to each cluster.

range of the gene expression activities in liver tissue that respond to RDX.

\section{Conclusion}

We have compared the similarity in gene expression responses of an in vitro system, primary hepatocyte cells, to an in vivo system, rat liver tissue, to determine how faithfully primary cells reflect toxicological responses of liver tissue exposed to an energetic compound, RDX. Primary cells were capable of expressing most genes present in liver tissue; however transcriptional level changes in primary cells reflected only a fraction of responses observed in liver tissue. This study indicates that care must be taken when toxicological data is derived from primary cells and extrapolated to whole animal organ toxicity effects.

\section{Methods \\ Animal exposures}

RDX (Purity > 99\%) was obtained from Stan Caulder (Naval Surface Warfare Center, Indianhead, MD) and was stored under absolute ethanol. Female Sprague-Dawley rats were from the in-house breeding colony (School of Pharmacy, University of Louisiana at Monroe [ULM]) maintained in accordance with the Guide for Use and Care of Animals (National Academy of Science, 1996). Breeders were from Harlan-Sprague Dawley (Madison, WI). Rats were housed with free access to pelleted rodent 
A

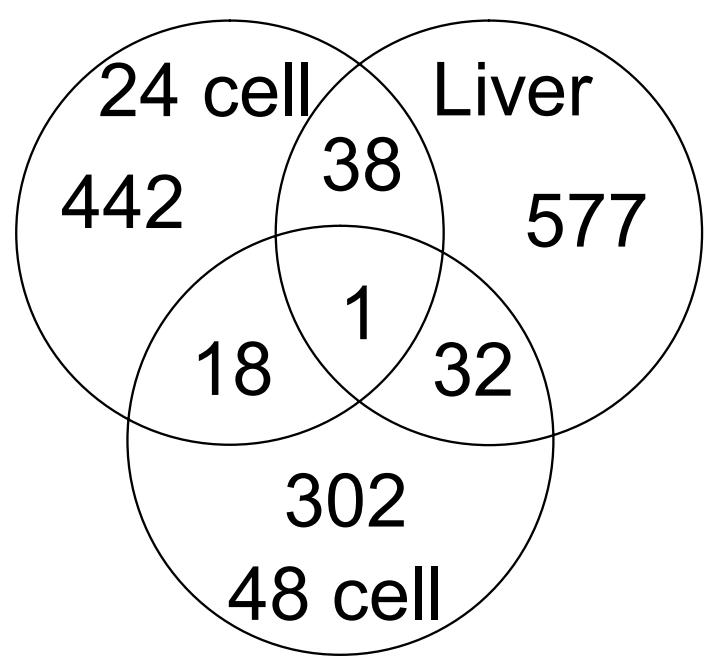

B

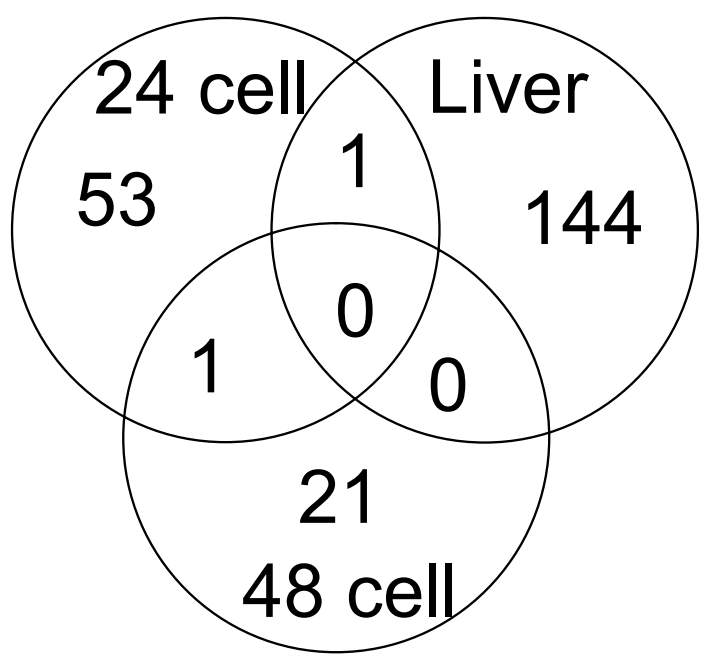

Figure 5

Common differentially expressed genes among all doses of exposed primary hepatic cells and liver tissue determined by ANOVA. Numbers in overlapping circles represent genes common to respective cells or tissue. 24 cell $=24$ $\mathrm{hr}$ exposed cells, 48 cell $=48 \mathrm{hr}$ exposed cells, and Liver $=$ liver tissue. A. ANOVA analysis $(\mathrm{p}<0.0 \mathrm{I})$. B. ANOVA analysis $(\mathrm{p}<$ $0.001)$.
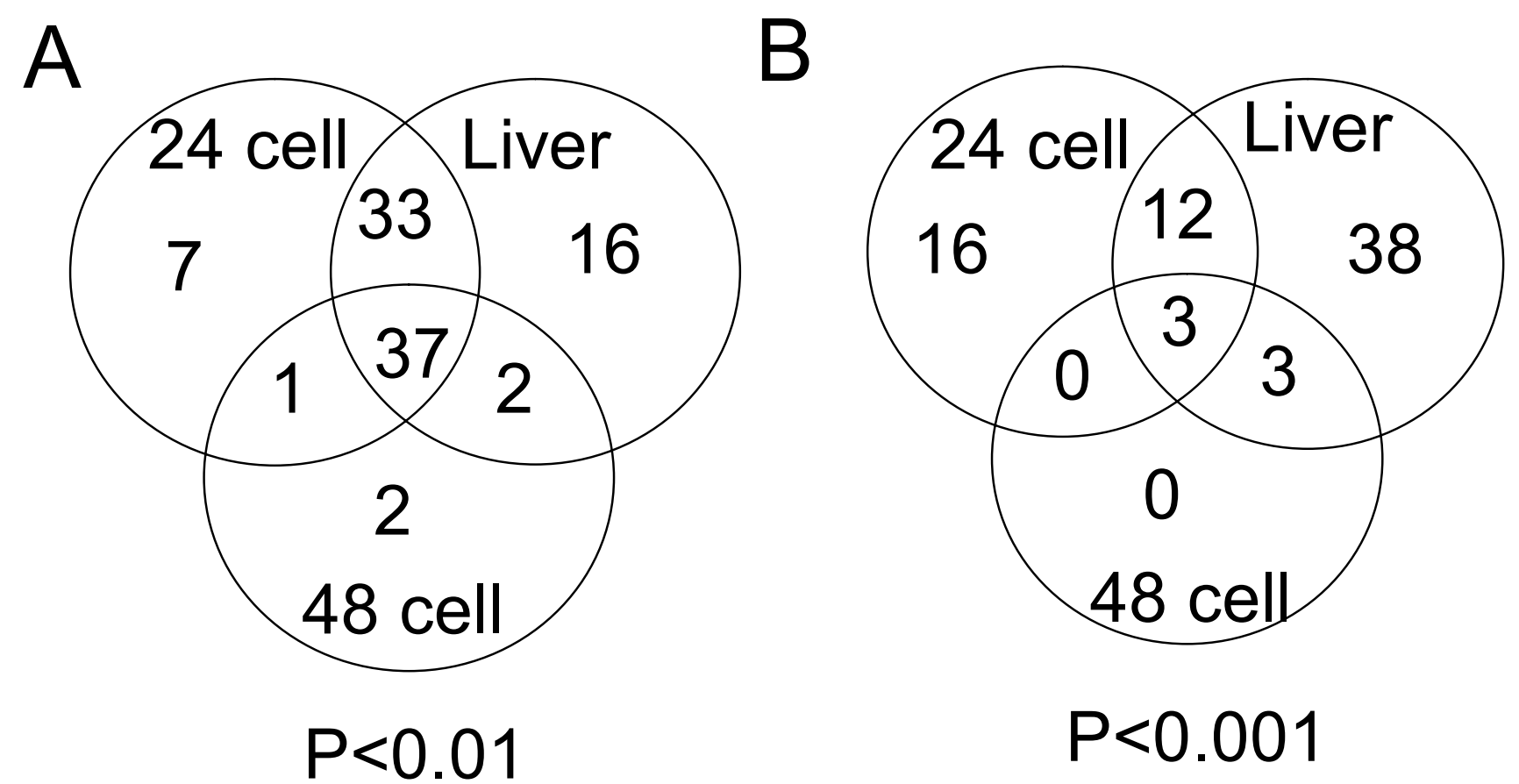

Figure 6

Common KEGG pathway terms among all doses of exposed primary hepatic cells and liver tissue. Numbers represent pathways common to respective cells or tissue. 24 cell $=24 \mathrm{hr}$ exposed cells, 48 cell $=48 \mathrm{hr}$ exposed cells, and Liver $=$ liver tissue. A. ANOVA analysis $(p<0.01)$. B. ANOVA analysis $(p<0.001)$. 
Table 2: Biological functions identified by GO term enrichment as uniquely affected by RDX in different treatments.

\begin{tabular}{|c|c|c|c|c|c|}
\hline Liver $24 \mathrm{hr}$ after exposure & EASE score & $24 \mathrm{hr}$ exposure of primary hepatocyte cells & EASE score & $\begin{array}{l}48 \mathrm{hr} \text { exposure of } \\
\text { primary hepatocyte } \\
\text { cells }\end{array}$ & EASE score \\
\hline metabolism & $9.00 \mathrm{E}-04$ & pathogenesis & $2.30 \mathrm{E}-03$ & physiological process & $3.75 \mathrm{E}-02$ \\
\hline lipid metabolism & $9.00 \mathrm{E}-04$ & lipid transport & $1.78 \mathrm{E}-02$ & $\begin{array}{l}\text { perception of abiotic } \\
\text { stimulus }\end{array}$ & 4.14E-02 \\
\hline fatty acid metabolism & $5.50 \mathrm{E}-03$ & amino acid metabolism & 2.77E-02 & protein metabolism & 4.27E-02 \\
\hline carboxylic acid metabolism & $5.60 \mathrm{E}-03$ & $\begin{array}{l}\text { energy derivation by oxidation of organic } \\
\text { compounds }\end{array}$ & $3.22 \mathrm{E}-02$ & & \\
\hline glutathione conjugation reaction & $7.00 \mathrm{E}-03$ & cholesterol metabolism & $3.33 \mathrm{E}-02$ & & \\
\hline ubiquitin-dependent protein catabolism & I.32E-02 & amino acid and derivative metabolism & $3.36 \mathrm{E}-02$ & & \\
\hline lipid biosynthesis & $1.88 \mathrm{E}-02$ & RNA processing & $3.90 \mathrm{E}-02$ & & \\
\hline sodium ion transport & $3.47 \mathrm{E}-02$ & & & & \\
\hline blood pressure & $4.00 \mathrm{E}-02$ & & & & \\
\hline
\end{tabular}

Data sets were comprised of significantly changed genes as identified by ANOVA in all doses within a tissue or cell exposure time. An enrichment of terms was considered significant when EASE scores were less than 0.05 and a within system false discovery rate was less than 0.125 .

chow (\#7012, Harlan/Teklad, Madison, WI) and tap water and with a $12 \mathrm{hr}$ light/dark cycle. One week prior to trials, groups of rats (175-225 gm) were housed individually in polycarbonate cages on hardwood bedding (Sani-chips, Harlan/Teklad, Madison, WI). Study protocols had prior approval by the ULM animal care and use committee.

Prior to treatment, food was withdrawn overnight. Five rats were randomly assigned to dose and exposed to single oral gavage doses of $0(1: 20, \mathrm{v} / \mathrm{v}$, dimethylsulfoxide vehicle control in corn oil), 47, and $94 \mathrm{mg} / \mathrm{Kg}$ RDX. At $24 \mathrm{hrs}$ post exposure animals were exsanguinated by cardiac puncture while under $\mathrm{CO}_{2}$ anesthesia, liver tissue samples harvested and immediately preserved in RNAlater (Ambion, Austin, TX). Concentrations of RDX in liver tissues were determined using the Environmental Protection Agency Method 8330 [14].

\section{Primary Hepatocyte Exposures}

Primary rat hepatocyte cell suspensions were prepared from fresh primary isolates shipped the day of isolation (Cambrex, Rockland, ME). Cell viability was checked upon arrival $(71 \pm 8 \%)$, seeded into flasks $\left(6 \times 10^{6}\right.$ cells in a T75 flask) and allowed to settle for $24 \mathrm{hrs}$ prior to dosing (dosing started at an estimated 36-hrs post isolation). Cells were dosed by exchanging the existing media with media spiked with a dimethylsulfoxide stock solution of the compound of interest (100 uL of dimethylsulfoxide solution into $10 \mathrm{~mL}$ media) or solvent alone for controls. Final media concentrations were $7.5,15$, or $30 \mathrm{mg} / \mathrm{L}$. Cells were maintained in an incubator $\left(37^{\circ} \mathrm{C}, 5 \% \mathrm{CO}_{2}\right.$ incubator, Nuaire, Plymouth, $\mathrm{MN}$ ) in hepatocyte culture media and supplements as per supplier instructions (Cambrex Hepatocyte Culture Media, CC-3199; HCM singlequot supplements, CC-4182). After the 24 or $48 \mathrm{hr}$ dose period, the cells were washed with phosphate buffered saline (GIBCO-InVitrogen, Grand Island, NY) and detached with $1 \times$ trypsin-EDTA (GIBCO-InVitrogen, Grand Island, NY). The cells were left in tryspin-EDTA no longer than 5 minutes. Freshly warmed media was then added to neutralize the trypsin. The cells were then transferred into a tube and centrifuged. RNAlater was added to the cell pellet and stored at $-20 \mathrm{C}$ until genomic analysis.

For the cytotoxicity assay, $2 \times 10^{4}$ cells/well were plated in Type 1 Collagen-coated, 96-well plate (BD Biosciences, Palo Alto, CA). Cells were dosed as described above. At the end of the 24 or $48 \mathrm{hr}$ exposure period, the medium from the plates was removed, and the cells washed with 1 $\times$ PBS. Freshly warmed Leibovitz medium $(100 \mu \mathrm{l})$ was introduced to each well followed by Neutral Red Stain (10 $\mu \mathrm{l})$. Leibovitz medium was selected because the medium has been shown not to interfere with the Neutral Red cytotoxicity assay (Sigma-Aldrich, In Vitro Toxicology Kit Tox4 ). The plates were incubated again for 2 more hours, after which the medium was removed and the Solubilization Solution $(200 \mu \mathrm{l})$ was added. The plates were placed on a shaker for 20 minutes to dissolve and mix any Neutral Red crystals formed. The plates were then read with a Tecan Safire (v 2.20 08/02) spectrophotometer at $540 \mathrm{~nm}$ and referenced at $690 \mathrm{~nm}$.

\section{Microarray Hybridizations}

Total RNA was isolated from RNAeasy preserved livers and primary hepatic cells using Qiagen RNAmini kits (Valencia, CA). Total RNA from three biological replicates at each dose were compared using a loop design with dye swaps (Figure 7) [15]. cDNA from 1 ug total RNA was synthesized, hybridized to arrays, and detected by secondary hybridization to Alexa647 and Cy3 dendrimer oligonucleotides using an Array900 detection kit per manufacturer's instructions (Genisphere, Hatfield, PA). cDNA was hybridized to $8 \mathrm{~K}$ Sigma/Compugen rat 70-mer oligonucleotide libraries arrayed on glass slides (Center for Applied Genomics, Newark, NJ http://www.cag.icph.org/ ). After secondary hybridization, slides were scanned using a 5 micron ChipReader microarray reader (BioRad, 


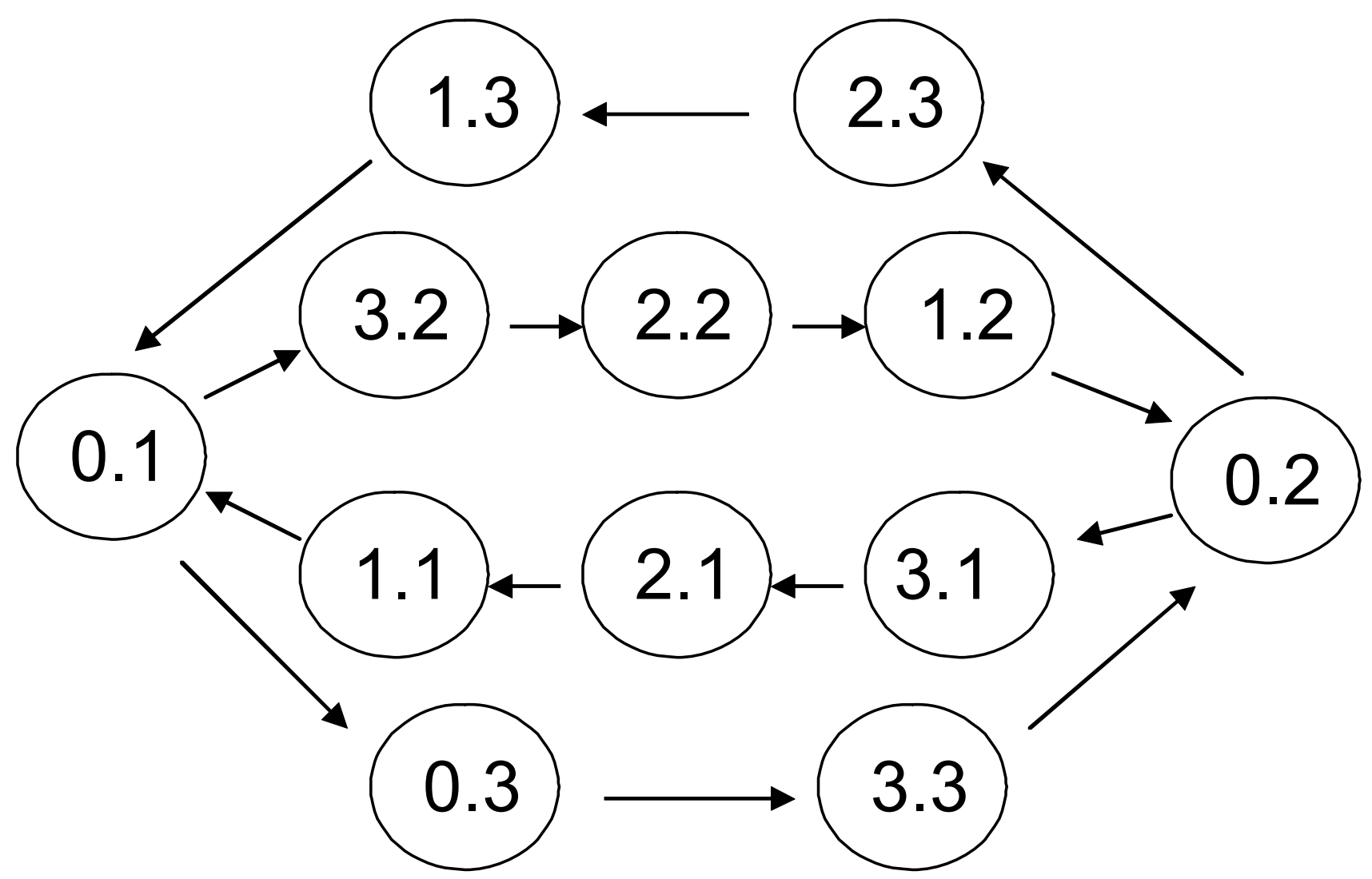

Figure 7

Looped hybridization scheme for analysis of liver and hepatic cell transcriptional responses. Circles represent treatment samples. For liver tissue samples, $0 . x=$ solvent control biological replicate $x, 1 . x=12 \mathrm{mg} / \mathrm{kg}$ dose biological replicate $x, 2 . x=24 \mathrm{mg} / \mathrm{kg}$ dose biological replicate $x, 3 . x=48 \mathrm{mg} / \mathrm{kg}$ dose biological replicate $x$. For 24 and $48 \mathrm{hr}$ exposures of primary hepatic cells to RDX, $0 . x=$ solvent control biological replicate $x, I . x=7.5 \mathrm{mg} / \mathrm{L}$ dose biological replicate $x, 2 . x=15 \mathrm{mg} / \mathrm{L}$ dose biological replicate $x, 3 . x=30 \mathrm{mg} / \mathrm{L}$ dose biological replicate $\mathrm{x}$. Arrows represent array hybridizations between respective samples where the arrowhead indicates dye labelling with Alexa 647 and the base of arrows indicate dye labelling with Cy3.

Hercules, CA). Spots were identified and quantified using VersArray software (BioRad).

\section{Gene expression analysis}

Local background signals were subtracted from each spot signal using the mean pixel density of a ring around that spot which is 4 pixels wide. Net intensity of spots was cross-channel normalized using locally weighted linear regression procedure (Leoss). The spot signals were transformed to logarithmic (base 2) values. Loess smoothing was applied to normalize data twice: first, within the arrays to minimize the dye bias, and then across the arrays to normalize data across all runs. Spots were considered present if the net spot intensity was 2 standard deviations greater than the mean local background intensity. Mixedmodel ANOVA was performed on the normalized intensities (not ratios) and resulting significance tests were used to identify differentially expression genes [16]. The afore- mentioned quality control, normalization, and statistical modelling were performed using JMP Genomics 2.0 from SAS Institute Inc. (Cary, NC. http://www.jmp.com). Pathway and gene ontology (GO) analyses for genes identified as differentially expressed by ANOVA were performed in ArrayTrack http://www.fda.gov/nctr/science/centers/toxi coinformatics/ArrayTrack/, and EASE [17]. We used the binomial test of Cho and Campbell [18] as implemented in PANTHER http://www.pantherdb.org to identify several classes of biological processes that were over or under represented in lists of these expressed genes compared to the array list that highlight potential functional differences in the tissue and cell types.

\section{List of abbreviations \\ DEG: Differentially Expressed Genes}

EASE: Expression Analysis Systematic Explorer 


\section{GO: Gene Ontology}

KEGG: Kyoto Encyclopedia of Genes and Genomes

RDX: hexahydro-1,3,5-trinitro-1,3,5-triazine

\section{Authors' contributions}

EJP drafted the manuscript, contributed to the design of the study, and assisted with array analysis. WB conducted the statistical analysis. XG conducted the array hybridizations. CYA conducted the primary cell exposures. RDW contributed to the statistical analysis. TMC contributed to the statistical analysis. SAM conducted the rat exposures. LSI participated in the design of the study, assisted with the rat and cell exposures, and contributed to the writing of the manuscript. All authors read and approved the final manuscript.

\section{Acknowledgements}

This work was supported by the Army Environmental Quality Program of the USACE. Permission was granted by the Chief of Engineers to publish this information.

This article has been published as part of BMC Bioinformatics Volume 7, Supplement 4, 2006: Symposium of Computations in Bioinformatics and Bioscience (SCBB06). The full contents of the supplement are available online at http://www.biomedcentral.com//47/-2/05/7? issue=\$4.

\section{References}

I. Layton D, Mallon B, Mitchell W, Hall L, Fish R, Perry L, Snyder G, Bogen K, Malloch W, Ham C, Dowd P: Data base assessment of the health and environmental effects of conventional weapons demilitarization: Explosives and their co-contaminants. In Report No. 83, Lawrence Livermore National Laboratory Livermore, CA; 1987.

2. ATSDR (Agency for Toxic Substances and Disease Registry): Toxicological Profile for RDX. In US Department of Health and Human Services Atlanta, GA; 1995.

3. US EPA (Environmental Protection Agency): Drinking Water Contaminant Candidate List. 2002 [http://www.epa.gov/OGWDW/ $\mathrm{ccl} / \mathrm{cclfs}$.html\#tablel]. Office of Water, US EPA

4. Woody RC, Kearns GL, Brewster MA, Turley CP, Sharp GB, Lake RS: The neurotoxicity of cyclotrimethylenetrinitramine (RDX) in a child; a clinical and pharmacokinetic evaluation. J Toxicol Clin Toxicol 1986, 24:305-319.

5. Goldberg DJ, Green ST, Nathwani D, McMenamin J, Hamlet N, Kennedy DH: RDX intoxication causing seizures and a widespread petechial rash mimicking meningococcaemia. J $R$ Soc Med 1992, 85:181.

6. Harrel-Bruder B, Hutchins KL: Seizures caused by ingestion of Composition C-4. Ann Emerg Med 1995, 26:746-748.

7. LeBouton AV: Molecular and Cell Biology of the Liver Boca Raton, FL, USA, CRC Press Inc; 1993.

8. Jessen BA, Mullins JS, de Peyster A, Stevens GJ: Assessment of Hepatocytes and Liver Slices as in Vitro Test Systems to Predict in Vivo Gene Expression. Toxicol Sci 2003, 75:208-222.

9. Tuschl G, Mueller SO: Effects of cell culture conditions on primary rat hepatocytes-cell morphology and differential gene expression. Toxicology 2006, 2 I 8:205-215.

10. Boess F, Kamber M, Romer S, Gasser R, Muller D, Albertini S, Suter $\mathrm{L}$ : Gene expression in two hepatic cell lines, cultured primary hepatocytes, and liver slices compared to the in vivo liver gene expression in rats: possible implications for toxicogenomics use of in vitro systems. Toxicol Sci 2003, 73:386-402.

II. Moschella F, Catanzaro RP, Bisikirska B, Sawczuk IS, Papadapoulos KP, Ferrante AW Jr, McKiernan JM, Hesdorffer CS, Harris PE, Maffei $A$ : Shifting gene expression profiles during ex vivo culture of renal tumor cells: implications for cancer immunotherapy. Oncol Res 2003, I 4: I33-45.

12. Mehrian Shai R, Reichardt JK, Ya-Hsuan H, Kremen TJ, Liau LM, Cloughesy TF, Mischel PS, Nelson SF: Robustness of gene expression profiling in glioma specimen samplings and derived cell lines. Brain Res Mol Brain Res 2005, I36:99-103.

13. Long RM, Rickert DE: Metabolism and Excretion of 2,6-dinitro [ $14 \mathrm{C}]$ toluene in vivo and in isolated perfused rat livers. Drug Metab Dispos 1982, 10:455-458.

14. US EPA (Environmental Protection Agency): Test Methods for Evaluating Solid Waste-Physical/Chemical Methods. In SWS846 Update II. Method 8330 Office of Solid Waste and Emergency Response, Washington, DC; 1994.

15. Kerr K, Churchill GA: Experimental design for gene expression microarrays. Biostatistics 200I, 2: |83-20I.

16. Wolfinger RD, Gibson G, Wolfinger ED, Bennett L, Hamadeh $H$, Bushel P, Afshari C, Paules RS: Assessing gene significance from cDNA microarray data via mixed models. J Comput Biol $200 \mathrm{I}$, 8:625-637.

17. Hosack DA, Dennis G Jr, Sherman BT, Lane HT, Lempicki RA: Identifying biological themes within lists of genes with EASE. Genome Biol 2003, 4:R70.

18. Cho RJ, Campbell MF: Transcription, genomes, function. Trends in Genetics 2000, 16:409-4I5.
Publish with Biomed Central and every scientist can read your work free of charge

"BioMed Central will be the most significant development for disseminating the results of biomedical research in our lifetime. "

Sir Paul Nurse, Cancer Research UK

Your research papers will be:

- available free of charge to the entire biomedical community

- peer reviewed and published immediately upon acceptance

- cited in PubMed and archived on PubMed Central

- yours - you keep the copyright
BioMedcentral 